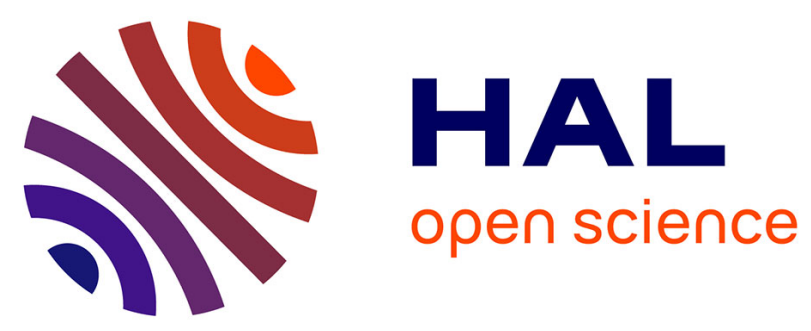

\title{
A nationwide analysis of incidence and outcome of breast cancer in the country of Surinam, during 1994-2003
}

Rachel S. Leeuwaarde, Martinus A. Vrede, Floyd Henar, Rob Does, Philip Issa, Emmett Burke, Otto Visser, Frank Rijmen, Anneke M. Westermann

\section{- To cite this version:}

Rachel S. Leeuwaarde, Martinus A. Vrede, Floyd Henar, Rob Does, Philip Issa, et al.. A nationwide analysis of incidence and outcome of breast cancer in the country of Surinam, during 1994-2003. Breast Cancer Research and Treatment, 2011, 128 (3), pp.873-881. 10.1007/s10549-011-1404-7 . hal00616291

\section{HAL Id: hal-00616291 \\ https://hal.science/hal-00616291}

Submitted on 22 Aug 2011

HAL is a multi-disciplinary open access archive for the deposit and dissemination of scientific research documents, whether they are published or not. The documents may come from teaching and research institutions in France or abroad, or from public or private research centers.
L'archive ouverte pluridisciplinaire HAL, est destinée au dépôt et à la diffusion de documents scientifiques de niveau recherche, publiés ou non, émanant des établissements d'enseignement et de recherche français ou étrangers, des laboratoires publics ou privés. 
A nation-wide analysis of incidence and outcome of breast cancer in the country of Surinam 1994-2003

6 Rob Does, $\mathrm{MD}^{4}$, Philip Issa, $\mathrm{MD}^{5}$, Emmett Burke, $\mathrm{MD}^{6}$, Otto Visser MD, PhD ${ }^{7}$, Frank

7 Rijmen, MSc, $\mathrm{PhD}^{8}$, Anneke M. Westermann, MD, $\mathrm{PhD}^{9}$

$9{ }^{1}$ Department of Medicine Department VU University Medical Center Amsterdam, The

10 Netherlands. Presently Department of Internal medicine, UMC Utrecht Heidelberglaan

11 100, 3584 CX Utrecht The Netherlands.

$12{ }^{2,3}$ Department of Pathology, Academic Hospital of Paramaribo, Paramaribo, Surinam.

$13{ }^{4}$ Department of Surgery, Diakonessen Hospital, Paramaribo, Surinam.

$14{ }^{5}$ Department of Internal Medicine, 's Lands hospital, Paramaribo, Surinam.

$15{ }^{6}$ Department of Surgery, St Vincentius Hospital, Paramaribo, Surinam.

$16{ }^{7}$ Comprehensive Cancer Center Amsterdam, the Netherlands

$17{ }^{8}$ Department of Clinical Epidemiology and Biostatistics, VU University Medical Center,

18 Amsterdam, The Netherlands.

$19{ }^{9}$ Department of Medical Oncology, Academic Medical Center, Amsterdam, The

20 Netherlands

21

$22{ }^{*}$ corresponding author. Department of internal medicine, UMC Utrecht, Heidelberglaan

231003584 CX Utrecht

24

25

26

27

28 


\section{Abstract}

7 Introduction: In this study we describe the incidence, treatment and outcome of breast

8 cancer (BC) in the period 1994-2003 in the South-American country of Surinam and

9 compare this with $\mathrm{BC}$ in the Netherlands.

10 Materials and methods: Pathology reports and hospital charts from all BC cases

11 diagnosed between 1994 and 2004 were retrieved from Surinam's single pathology

12 laboratory and its 5 hospitals. Data on demographics, tumor characteristics, treatment

13 and follow-up were gathered. We compared our data to BC statistics of first generation

14 immigrants from Surinam to the Netherlands.

15 Results: 421 patients were diagnosed with $\mathrm{BC}$ during the study period. The age-

16 adjusted incidence rate was 26 per 100,000 compared to 65/100,000 in first generation

17 Surinamese women in the Netherlands. The majority had a fairly advanced stage at

18 presentation, with $60 \%$ of tumors larger than $2 \mathrm{~cm}$ and $41.6 \%$ with lymph node

19 involvement. Because of the absence of radiotherapy facilities, local treatment in most

20 patients was radical mastectomy. Adjuvant hormonal therapy (51.6\%) was administered

21 more frequently than adjuvant chemotherapy (20.3\%). A significant number of patients

22 was lost to follow-up, resulting in a median follow-up duration of only 23 months. The

23 five year overall survival was $79 \%$.

24 Conclusions: BC incidence in Surinam is low compared to that in the western world, but 25 the advanced stage at diagnosis, the low utilization of systemic adjuvant therapy and the 26 inadequate follow-up may lead to poor outcomes. A number of steps are underway to 27 improve the level of cancer care in Surinam. 


\section{Introduction}

$9 \quad \mathrm{BC}$ is the most common malignancy among women worldwide. However, the incidence

10 is highest in developed countries, and relatively low in the developing world[1].

11 The republic of Surinam is a former Dutch colony situated in South America, that gained

12 independence in 1975. Its history of colonization, slave labor and contract laborers has

13 led to great ethnic diversity in its population of almost 500,000[2]. The major ethnic

14 groups are of Indian descent (the so called "Hindustani", 27.4\%), or mixed African

15 descent (the so called "Creoles", 17.7\%), Marroons (descendants of runaway

16 slaves, 14.7\%) and Javanese (descendants of Indonesian contract laborers, 14.6\%)[3]. In

17 the 1970s and 1980s, after independence and during a period of civil unrest, mass

18 emigration to the Netherlands took place, so that the Netherlands now has a population

19 of almost 350,000 originally from Surinam[4].

20 In the year 2002 the Gross Domestic Product (GDP) per capita was US\$ 4, 447. The 21 annual per capita health expenditure was US\$385, corresponding to an expenditure of $228.6 \%$ of the GDP[5]. The equivalent numbers for the USA in 2002 were US\$ 36, 056 for 23 GDP, and US $\$ 5,274$ or $14.6 \%$ of the GDP for health[6].

24 There are five hospitals in Surinam, four of which are in the capital of Paramaribo.

25 Medical specialists have all been trained, at least partly, in first world hospitals, mostly in 26 the Netherlands. Surinam has one pathology laboratory in Paramaribo, where all

27 biopsies and surgical specimens obtained anywhere in the country are sent.

28 Radiotherapy was not available in Surinam during the study period, so that patients who 29 were eligible for radiotherapy had to go out of the country to receive it. A substantial part 30 of the population has limited health care coverage and many patients have to contribute 31 to the cost of health care out of private funds. There is at present no cancer registry. 
2 Because of the paucity of data on BC in Surinam, the aim of this study was to

3 retrospectively investigate the epidemiology, treatment and outcome of $\mathrm{BC}$ over the last

4 decade in order to establish the baseline situation for future health care planning and

5 evaluation. We compared these data to $\mathrm{BC}$ statistics of first generation immigrants from

6 Surinam to the Netherlands.

\section{Methods}

12 Between June 1, 2005, and September 30, 2005, data were collected for all patients 13 with a pathological diagnosis of invasive BC between January 1, 1994, and December $1431,2003$.

15 After retrieval from the pathology laboratory archives, the patient charts in the different

16 hospitals were collected and hand-searched for the following data: patient

17 demographics; tumor characteristics (including TNM-stage, grade, and hormone

18 receptor status); treatment characteristics and follow-up data. The last date of follow-up

19 was the last recorded hospital contact, or death of patient. During the study period, there 20 were no national guidelines for treatment of breast cancer.

21 This study was approved by the Ministry of Health, the National Medical Ethics Board, 22 the boards of directors and the medical staffs of all hospitals in Surinam. The medical 23 ethics committee of Surinam granted a waiver for informed consent for this archival 24 study. Data on Surinamese women with breast cancer in the Netherlands were retrieved 25 from the Netherlands Cancer Registry. We used data for the provinces of North-Holland 26 and Flevoland, which host $35 \%$ of the Surinamese population in the Netherlands.

\section{Analysis}

29 A database was made in Access ${ }^{\odot}$ to store all data. The interval between the different 30 therapies was calculated in this program. Kaplan-Meyer curves and survival times were 31 calculated in SPSS ${ }^{\odot}$. The age standardized incidence rate was calculated using the 
World Standard population.

\section{Results}

\section{Incidence}

16 From January 1, 1994, until December 31, 2003, 421 patients were diagnosed with BC

17 in Suriname, two were male. The median incidence was 38,5 per year with a peak of 70

18 patients in the year 2000. The crude incidence rate in the study period was $15,7 / 100,000$

19 per year. The age adjusted incidence rate was 28 per 100,000 per year (Table 1). The

20 age adjusted incidence rate for first generation Surinamese women in the Netherlands in 21 the same period of time was 65 per 100,000 per year (Table 1).

\section{Patient characteristics}

24 The median age at $B C$ diagnosis was 55 years, with a range of 26 to 90 . BC incidence is

25 higher in Surinamese women in the Netherlands than in Surinamese women in Surinam, 26 and this seems to be especially true for women over 55 (Figure 1). BC occurs more 27 often in Creoles (35,7/100,000/year), than in Hindustani (18,2/100,000/year) and 28 Javanese women $(20,8 / 100,000 /$ year $)$.

29 Data on parity $(n=173)$ and age at first pregnancy $(n=61)$ were not available for the 30 majority of patients. Data on lactation and duration of lactation were so scarce that they 
were left out of this report.

\section{Tumor characteristics}

4 In Surinam, ductal cancers were most common (94\%), with a minority of lobular tumors

$5 \quad(1.7 \%)$ and tumors of unknown origin (4.3\%). (Table 3$)$

6 More than $60 \%$ of all tumors were T2 $(>20 \mathrm{~mm}$ and $<50 \mathrm{~mm})$ and larger, while less than a

7 quarter were $\mathrm{T} 1(<20 \mathrm{~mm})$. In almost $15 \%$ of cases, tumor size was not known, either

8 because the patients never came back after the diagnostic biopsy for further treatment,

9 or because they were not eligible for surgery due to tumor spread at presentation.

10 The lymph node status was known for 323 patients, with almost equal numbers with

11 tumor-positive $(\mathrm{N}+)$ and tumor-negative (N0) axillary nodes. The 96 patients with an

12 unknown axillary node status were either patients who only had a diagnostic biopsy and

13 did not return for further treatment or had an advanced stage at presentation and were

14 not eligible for surgery.

15 The hormone receptor status was known for 69 patients only (Table 3), $40 \%$ of whom

16 had a positive estrogen receptor (ER) and/or progestagen receptor $(\mathrm{PgR})$. All but two of

17 these hormone receptor tests were done after 2000.

18 At time of presentation a small number of patients (5.7\%) had distant metastases.

19 The majority of tumors for which the histological grade was known, was poorly

20 differentiated according to the Bloom-Richardson classification. The mitotic activity index

21 (MAl), which was determined in Surinam from the year 2000, was known for 95 tumors,

22 of which $53.7 \%$ had a MAI $\leq 10$ mitotic figures/10 hpf and $46.3 \%$ had a MAl $>10$ mitotic

23 figures/10 hpf.

\section{Treatment}

26 A large majority $(79.7 \%)$ of patients underwent surgery. Modified radical mastectomy

27 was the procedure most often performed, with some form of breast conserving therapy

28 for a minority of patients (Table 4 ). The $20.3 \%$ of patients who did not receive surgery, 29 were diagnosed with BC, but either never came back for further treatment or had an 30 advanced stage of $B C$ and were thus not eligible for surgery. 
1 Hormone therapy was prescribed for 216 (51.6\%) patients. The lymph node status was

2 known for 186 of these patients, and $62 \%$ of $\mathrm{N}+$ patients and $52 \%$ of $\mathrm{N} 0$ patients

3 received hormone therapy.

4 In the 78 N0 patients who received hormone therapy, the indications for hormone

5 therapy were T1 tumor with BR $3(n=4), T 3$ or T4 tumor $(n=9)$, T2 with a BR2 or 3

$6(n=27)$. For 38 patients the indication for hormone therapy was not specified. 18 of 26

7 patients who had positive hormone receptors received hormone therapy. The 8 patients

8 with a positive hormone receptor who did not receive hormone therapy died or were lost

9 to follow-up soon after diagnosis.

10 A fifth of all patients received adjuvant chemotherapy. This was not appreciably

11 influenced by the size of the primary tumor. Chemotherapy was given to $35.1 \%$ of all

12 node positive $(\mathrm{N}+)$ patients. Fifty-one percent of $\mathrm{N}+$ women $<50$ years and $20 \%$ of $\mathrm{N}_{+}$

13 women $>50$ years received chemotherapy. Seventeen percent of N0 women $<50$ years

14 and $4 \%$ of N0 women $>50$ years received chemotherapy.

15 Thirty percent of all patients who were eligible for chemotherapy according to the 2005

16 Surinam guidelines. (obviously not available during the study period) actually received it

17 in our cohort.

19 Thirty-three patients (of 42 who had breast conserving surgery) were irradiated abroad

20 after lumpectomy. Twenty-six patients received radiotherapy after radical mastectomy.

21 The indication for adjuvant radiotherapy was irradical resection in five patients, T3 tumor

$22(n=3)$, T4 tumor $(n=3)$, age $<35$ years $(n=2)$, ER-/PgR- $(n=2)$, and grossly positive lymph

23 nodes (>N2 in 7 patients). For 4 patients who were treated with adjuvant radiotherapy

24 after mastectomy, the indication could not be retrieved from the available records.

25

\section{Treatment duration}

27 The median time from the date of diagnosis until the date of surgery in Surinam was 17

28 days, with not much variation between the different hospitals in Paramaribo. The median

29 time between breast conserving surgery in Surinam and radiotherapy abroad was 11

30 weeks. For the 26 patients who received radiotherapy after mastectomy, the median

31 time between mastectomy and radiotherapy was 11.5 weeks. 
The median time between surgery and second treatment modality, either chemotherapy

2 or radiotherapy was 9 weeks. The median time from the end of the first to the start of the

3 second adjuvant treatment modality was 12 weeks.

\section{Outcome}

6 Follow-up data of 384 (91.7\%) patients were available, but median follow-up was only 23

7 months. Five-year follow-up was available for 73 patients. The five year overall survival

8 for these patients was $79 \%$, with a median of 110 months (Figure 2 ).

10 During follow-up, 45 patients were diagnosed with distant metastases, 47 with a

11 locoregional relapse and 27 with both distant spread and locoregional relapse. Patients

12 who received breast conserving therapy developed locoregional relapse in $9.1 \%$ of

13 cases, while in patients who underwent mastectomy the locoregional relapse rate was

$1420.5 \%$.

15 The mean disease free survival was 100 months (Figure 2), and highly correlated to T

16 stage, with 111 months for T1 tumors, 94 months for T2 tumors, 77 months for T3

17 tumors and for T4 tumors 44 months. For patients with negative lymph node status

18 mean survival was 116 months and for positive lymph node status 78 months (Figure 3).

\section{Discussion}

28 In this retrospective population-based survey the incidence of $B C$ in Surinam was

29 studied over a 10-year period. The strength of this study lies in the fact that all

30 pathology-confirmed diagnoses in the country were included in the analysis, and all

31 hospitals participated. The main weakness is the paucity of follow-up data with a median 
follow-up of less than 2 years, which impedes discussion of outcome. Although all

2 pathologically confirmed $\mathrm{BC}$ diagnoses in Surinam during the study period were included

3 in the analyses, it is conceivable that additional women were diagnosed with advanced

$4 \quad$ BC during the study period without tumor biopsies or surgery. The absence of a national

5 cancer registry in the country makes it impossible to estimate or correct for this in any

6 way. However, this is the first population-based study to look at individual demographic,

7 tumor and treatment data.

9 The crude cancer incidence rate in Surinam increased from 9.5/100 000 in 1964-1976[7]

10 to $16.7 / 100000$ in 1980-2000[8], which is similar to our results. The rise in BC incidence

11 over the past decades is seen worldwide[9,10] and has been mostly correlated with

12 changes in reproductive factors. This may to a large degree account for the lower BC

13 incidence in developing countries vs. the western world[11;12]. Although increasing, the

14 mean age at first birth in Surinam is still low at 21 years[5], compared to over 28 years in

15 most western European countries[13]. In addition, mean parity in Surinam was 2.7

16 children per women in 2000[3], while in the Netherlands it was only 1.7 (2001-2003)[13].

17 Interestingly, the incidence of $\mathrm{BC}$ in Surinamese women in Surinam was considerably

18 lower than the incidence of first generation Surinamese women in the Netherlands

19 (Figure 1). The main possible explanation is thought to lie in demographic changes, with

20 Surinamese women in the Netherlands adapting to Dutch reproductive statistics with

21 less children at a higher age, although increased detection due to public awareness and

22 screening mammography programs may also play a part.

23

24 The median age at BC diagnosis was lower than the median age in the western world, 25 albeit fairly high compared to other low-income countries, underlining the in-between 26 state of development of Surinam society[11;12;14]. A confounding factor could be the 27 relatively low life expectancy of women in Surinam (69 years at birth[5], versus 80 in the 28 USA[6]), especially in view of the fact that $43 \%$ of new BC cases in the USA are 29 diagnosed in women older than 65 years. The most important competing risk for death in 30 Surinam is cardiovascular disease, which has a high mortality because (preventive) care 31 is not always optimized. 
The fact that the proportion of Creole BC patients is higher than would be expected by

2 the distribution of ethnicities in the population, may both be explained by genetic factors

3 comparable to the incidence data for e.g. African-Americans in the USA, but also

4 because cardiovascular disease is much more prevalent in Hindustanis, the largest

5 ethnic group.

7 Women presented with late stage BC more often than in the western world, e.g. $41.6 \%$

8 of patients had lymph node involvement at time of diagnosis, whereas during the same

9 time period this was only $30 \%$ in the USA and $31 \%$ in the Netherlands[15]. More

10 advanced stage at diagnosis is commonly found in developing countries[14], and is

11 thought to be related to lack of universal coverage, lack of screening programs, and fear

12 of cancer in general. Tumor size and stage decreased in the western world since the

13 introduction of mammography in the Netherlands in the last decades of the $20^{\text {th }}$

14 century[16-18], and this went hand in hand with increased public awareness and

15 reduced taboo status of the disease[19;20]. In Surinam, the vivid culture of traditional

16 medicine and taboo status of BC, almost certainly contribute to a more advanced stage

17 at diagnosis. However, the convergence of both incidence and stage of $B C$ in first

18 generation immigrants from Surinam to the native Dutch population challenges the size

19 of the effect of different attitude and beliefs. It underscores both the relationship between

20 poor socioeconomic status and access to health care, and the positive effect of BC

21 campaigns to enhance BC awareness and possibly of screening[21].

22

23 Although data on tumor size and lymph node status were generally available from the 24 pathology lab, other prognostic and predictive factors were harder to interpret. We found 25 a discrepancy between the Mitotic Activity Index (MAI) and Bloom-Richardson grading.

26 The majority of tumors had low MAI (under $10 \mathrm{hpf}$ ) but this was paired with high tumor 27 grades according to Bloom-Richardson. Grading is generally considered more subjective 28 and less reproducible than MAI. According to several authors MAI is a strong, widely available, easily assessable, inexpensive, well-reproducible prognosticator, if the 30 protocol is carefully followed. Fixation delay for as long as 24 hours after extirpation of 31 the tumor does not decrease the accuracy of the MAI, in contrast to BR evaluation[22]. 
1 In a country with limited resources, MAI could prove to be more reliable than grading,

2 but short of central pathology revision, there is no way of knowing what was most

3 accurate or consistent in Surinam.

4 Because of the absence of immunohistochemistry (IHC) technology in the pathology

5 laboratory in Surinam to determine hormone receptor status, paraffin-embedded archival

6 tissues were sent to the Netherlands to determine the receptor status of the tumor

7 whenever deemed necessary for treatment decisions. Unfortunately, only a minority of

8 patients had tissue sent to the Netherlands, and most of them had a negative receptor

9 status. Is this an accurate estimation? False negatives of hormone receptor are not

10 uncommon, especially with increasing time delay before tissue fixation, increased

11 duration of fixation and type of fixative, all of which may have been the case in our

12 patient cohort. False negatives increase especially in $\mathrm{BC}$ with a low receptor positivity

13 such as is typically seen in patients of African descent[23-26]. At present it is impossible

14 to say whether this played a part in our study population, but the lack of IHC to

15 determine predictive markers is bound to hamper treatment decision making, and

16 possibly outcome. Thus, since hormone receptor status was known for only 69 patients,

17 prescription of adjuvant hormone therapy was mostly blinded to ER-status. This seems

18 not unreasonable, in view of the uncertainty about the quality of the assessments, and

19 the mild cost and systemic effects of hormone therapy.

21 The indications for adjuvant systemic therapy for BC have broadened over the past 22 decades. Although regional differences exist, in general adjuvant systemic therapy is 23 prescribed for larger tumors, $\mathrm{N}+$ tumors and small tumors that are poorly differentiated.

24 No guideline existed in Surinam during the study period, but in 2005 the National 25 Oncology Committee developed a BC treatment guideline based on both Dutch and 26 American (USA) guidelines[27;28], although in some cases the suggested drug 27 regimens differed to suit Surinam's economical situation[5]. Indications for adjuvant 28 systemic therapy according to this government-approved guideline were compared to 29 the proportion of patients receiving such therapy in the study cohort. It should be noted 30 that over the study time period, in western countries adjuvant chemotherapy practice 31 was also considerably more conservative than it is now. The aim of the comparison was 
mainly to assist in future health care planning.

2 A minority of patients who would be eligible for adjuvant chemotherapy according to the 3 guideline actually received it (30\%). Based on western experience after the introduction

4 of national guidelines[29], this number could go up to at least $70 \%$ for chemotherapy,

5 which means that the number of patients that will receive adjuvant chemotherapy may

6 double or even triple.

8 The treatment interval between the different treatment modalities is a predictor for 9 outcome, with a long treatment interval as an unfavorable factor. Compared to the 10 Netherlands, the median interval between diagnosis and surgery was shorter (17 days

11 vs. around 28 days), which points to the absence of long waiting lists for surgery so 12 common in the Netherlands. However, treatment intervals between surgery and

13 chemotherapy compared unfavorably to the Netherlands (9 vs. 4 weeks). We speculate 14 that the lack of availability of cytotoxic drugs in Surinam may in some case account for 15 the delay, but lack of a sense of urgency in both doctors and patients may also play a 16 part.

17 The time between surgery and radiotherapy was approximately 11 weeks. In the

18 Netherlands an 8 week interval is considered the upper limit of what is acceptable, with

19 a preference for 4-6 weeks. Because of the absence of radiotherapy facilities within the 20 country, a longer interval may have been unavoidable in this group. In view of this, it 21 may be worth considering advising radical mastectomy instead of breast conserving 22 therapy for all patients, until radiotherapy will be available in the country.

24 For a relatively large part of our cohort (20-25\%), no data on lymph node status or local 25 treatment were available. Some of these patients may not have received local treatment 26 because of advanced stage of disease at time of diagnosis, but we speculate that others 27 never returned for further treatment. This is consistent with the relatively short length of 28 follow-up, in spite of our concerted efforts to track down the disease course of all 29 patients. We were unable to determine whether patients in general did not return for 30 follow-up because disease was uncontrolled, or because they were asymptomatic. In 31 either case, this may have biased the survival data, which raises doubt about their 
1 validity, even though obvious trends such as worse outcome for higher stages could be

2 confirmed.

\section{Conclusion}

5 In this study we have shown the feasibility of conducting a nationwide epidemiologic

6 survey in Surinam. Most of our findings could be related to the demographics of Surinam

7 and the low-resource status of the economy. The introduction of the Surinam BC

8 treatment guideline, the planned introduction of immunohistochemistry, and the

9 anticipated introduction of radiotherapy in late 2010 are expected to ameliorate

10 diagnosis and treatment of BC patients in Surinam. The projected start of a national

11 cancer registry, combined with a recently improved continued medical education

12 program will further enhance these goals. Improvement in $\mathrm{BC}$ awareness and possible

13 implementation of $\mathrm{BC}$ screening programs will take much longer.

\section{Acknowledgements}

19 We are very grateful for the participation and assistance of the following persons and

20 institutions in this study:

21 Surinam:

22 Boards of hospitals \& medical staffs

23 Ministry of health: M. Eersel, MSc

24 Administrative staff of all participating hospitals

25 Paramaribo, Surinam:

\section{Academisch Ziekenhuis}

27 Surgery: R.B. Girjasing, MD. S. Nannan Panday, MD

28 Internal medicine: H.D. Chee, MD C.H. Adhin, MD, I.J. Lie Kiauw, MD J. Loor, MD, J.E.

29 Anijs, MD

30 Diakonessenhuis

31 Surgery: A.E. Bergen MD 
1 Internal medicine: S. Vreden, MD, E. Dams, MD, B.O. Hewitt, MD, M. van Eer, MD

2 's Lands Hospital

3 Surgery: J.H. de Bye, MD

4 Internal medicine: S Nannan Panday†, MD

5 St Vincentius Hospital

6 Surgery: M.N. Mohab Ali, MD

7 Internal medicine: A. Cameron, MD H. Dissels, MD

8 Nickerie, Surinam:

9 Streekziekenhuis Nickerie

10 Surgery: A.S. Li Fo Sjoe, MD

11 Pediatrics: N. Braafheid, MD

12

13 Vu medical center, Amsterdam, The Netherlands

14 W.R. Gerritsen MD, PhD

15

\section{Conflict of interest statement}

17 No conflict of interest

18

19

20

21

22

23

24

25

26

27

28

29

30

31 


\section{Reference List}

[1] L.A.Brinton, J.Benichou, M.D.Gammon, D.R.Brogan, R.Coates, J.B.Schoenberg. Ethnicity and variation in breast cancer incidence, Int.J.Cancer, 73, (1997) 349355.

[2] Pan American health organization (PAHO). www.paho.org/English/DD/AIS/cp 740.htm . 2010.

Ref Type: Internet Communication

[3] Algemeen bureau voor de statistiek: Census kantoor. Suriname census 2004 volume 1. 1-9. www.statistics-suriname.org . 2010.

Ref Type: Internet Communication

[4] Centraal Bureau voor de statistiek. The Hague/Heerlen. http://statline.cbs.nl/statweb/ . 25-4-2010.

Ref Type: Internet Communication

[5] World Health Organization (WHO). www.who.int/countries/sur/en/ (2002) . 2010. Ref Type: Internet Communication

[6] World Health Organization (WHO). www.who.int/countries/USA/en/ (2002) . 2010. Ref Type: Internet Communication

[7] Brathwaite AF. Breast Cancer in Surinam., Trop Georgr.Med, 31, (1979) 81-85.

[8] D.R.Mans, R.N.Mohamedradja, A.R.Hoeblal, R.Rampadarath, S.S.Joe, J.Wong, P.Ramautar, R.Mahabier, M.A.Vrede. Cancer incidence in Suriname from 1980 through 2000 a descriptive study, Tumori, 89, (2003) 368-376.

[9] J.L.Kelsey, M.D.Gammon. The epidemiology of breast cancer, CA Cancer J.Clin., 41, (1991) 146-165.

[10] T.J.Key, P.K.Verkasalo, E.Banks. Epidemiology of breast cancer, Lancet Oncol., 2, (2001) 133-140.

[11] I.D.Gukas, B.A.Jennings, B.M.Mandong, A.N.Manasseh, I.Harvey, S.J.Leinster. A comparison of the pattern of occurrence of breast cancer in Nigerian and British women, Breast, 15, (2006) 90-95.

[12] A.N.Hisham, C.H.Yip. Overview of breast cancer in Malaysian women: a problem with late diagnosis, Asian J.Surg., 27, (2004) 130-133.

[13] H.K.Snick, J.L.Evers, J.A.Collins. An update on the age of subfertile couples in Walcheren: age at registration mirrors increasing age at first birth, Hum.Reprod., 20, (2005) 572-573. 
[14] I.Harirchi, M.Karbakhsh, A.Kashefi, A.J.Momtahen. Breast cancer in Iran: results of a multi-center study, Asian Pac.J.Cancer Prev., 5, (2004) 24-27.

[15] Surveillance Epidemiology, and End results (SEER). 2010. Ref Type: Internet Communication

[16] Y.Aubard, D.Genet, J.L.Eyraud, P.Clavere, N.Tubiana-Mathieu, H.J.Philippe. Impact of screening on breast cancer detection. Retrospective comparative study of two periods ten years apart, Eur.J.Gynaecol.Oncol., 23, (2002) 37-41.

[17] J.A.van Dijck, J.H.Hendriks, R.Holland, L.J.Schouten, A.L.Verbeek. [Alterations of stage distribution for breast cancer since the implementation of national screening program in the Netherlands during 1989-1995], Ned Tijdschr Geneeskd, 144, (2000) 1119-1124.

[18] J.Fracheboud, S.J.Otto, J.A.van Dijck, M.J.Broeders, A.L.Verbeek, H.J.de Koning. Decreased rates of advanced breast cancer due to mammography screening in The Netherlands, Br.J.Cancer, 91, (2004) 861-867.

[19] D.R.Lannin, H.F.Mathews, J.Mitchell, M.S.Swanson, F.H.Swanson, M.S.Edwards. Influence of socioeconomic and cultural factors on racial differences in late-stage presentation of breast cancer, JAMA, 279, (1998) 18011807.

[20] B.A.Miller, B.F.Hankey, T.L.Thomas. Impact of sociodemographic factors, hormone receptor status, and tumor grade on ethnic differences in tumor stage and size for breast cancer in US women, Am.J.Epidemiol., 155, (2002) 534-545.

[21] I.Stirbu, A.E.Kunst, F.A.Vlems, O.Visser, V.Bos, W.Deville, H.G.Nijhuis, J.W.Coebergh. Cancer mortality rates among first and second generation migrants in the Netherlands: Convergence toward the rates of the native Dutch population, Int.J.Cancer, 119, (2006) 2665-2672.

[22] J.P.Baak, P.J.van Diest, F.J.Voorhorst, W.E.van der, L.V.Beex, J.B.Vermorken, E.A.Janssen. Prospective multicenter validation of the independent prognostic value of the mitotic activity index in lymph node-negative breast cancer patients younger than 55 years, J.Clin.Oncol., 23, (2005) 5993-6001.

[23] V.W.Chen, P.Correa, R.J.Kurman, X.C.Wu, J.W.Eley, D.Austin, H.Muss, C.P.Hunter, C.Redmond, M.Sobhan, . Histological characteristics of breast carcinoma in blacks and whites, Cancer Epidemiol.Biomarkers Prev., 3, (1994) 127-135.

[24] H.Furberg, R.Millikan, L.Dressler, B.Newman, J.Geradts. Tumor characteristics in African American and white women, Breast Cancer Res.Treat., 68, (2001) 3343. 
[25] A.Rhodes, B.Jasani, D.M.Barnes, L.G.Bobrow, K.D.Miller. Reliability of immunohistochemical demonstration of oestrogen receptors in routine practice: interlaboratory variance in the sensitivity of detection and evaluation of scoring systems, J.Clin.Pathol., 53, (2000) 125-130.

[26] C.R.Taylor, S.R.Shi, B.Chaiwun, L.Young, S.A.Imam, R.J.Cote. Strategies for improving the immunohistochemical staining of various intranuclear prognostic markers in formalin-paraffin sections: androgen receptor, estrogen receptor, progesterone receptor, p53 protein, proliferating cell nuclear antigen, and Ki-67 antigen revealed by antigen retrieval techniques, Hum.Pathol., 25, (1994) 263270.

[27] Dutch guideline for breast cancer. www.oncoline.nl/mamma/mammacarcinoom . 2010.

Ref Type: Internet Communication

[28] National Comprehensive Cancer Network. Practical guidelines in oncologyv.2.2006. http://www.nccn.org/index.asp . 2010.

Ref Type: Internet Communication

[29] A.Wockel, C.Kurzeder, V.Geyer, I.Novasphenny, R.Wolters, M.Wischnewsky, R.Kreienberg, D.Varga. Effects of guideline adherence in primary breast cancer-a 5-year multi-center cohort study of 3976 patients, Breast, 19, (2010) 120-127.

\section{Figure legends}

Figure 1: Age specific breast cancer incidence in Surinam and in Surinamese women in the Netherlands

Figure 2: Overall \& disease free survival of breast cancer patients in Surinam

Figure 3: Overall cumulative survival of breast cancer patients with $\mathrm{N} / \mathrm{N}+$ in Surinam Table 1: Characteristics of breast cancer patients in Surinam and

Surinamese women in the provinces North-Holland and Flevoland in the

Netherlands, 1994-2003

Surinam

Number of patients

$\left(\mathrm{ASR}^{*}\right)$
The Netherlands

Number of patients

$\left(\mathrm{ASR}^{*}\right)$

\section{Total}




\begin{tabular}{|c|c|c|c|c|}
\hline 1994-1998 & $167(25)$ & \multicolumn{3}{|c|}{$88(62)$} \\
\hline 1999-2003 & $252(31)$ & & $108(68$ & \\
\hline \multicolumn{5}{|l|}{ Age } \\
\hline$<30$ & 3 & 0.7 & 2 & 1.0 \\
\hline $30-39$ & 43 & 10.3 & 29 & 14.8 \\
\hline $40-49$ & 108 & 25.8 & 42 & 21.4 \\
\hline $50-59$ & 94 & 22.4 & 53 & 27.0 \\
\hline $60-69$ & 94 & 22.4 & 44 & 22.4 \\
\hline$>70$ & 75 & 17.9 & 26 & $13 \cdot 3$ \\
\hline Unknown & 2 & 0.5 & - & \\
\hline
\end{tabular}

$2 \quad{ }^{*} \mathrm{ASR}=$ age standardized rate per 100,000 women per year

3

4

5

6

7

8

9

10

11

12

13

14 Table 2 Characteristics of breast cancer patients in Surinam 1994-2003

15

Strata

Number of patients

Incidence
rate per
100.000/year

Feb 12, 2007 RLE 
Ethnicity

\begin{tabular}{|c|c|c|c|}
\hline Creole & 156 & 37.2 & $35 \cdot 7$ \\
\hline Marroons & 8 & 1.9 & 2.2 \\
\hline Hindustani & 123 & 29.4 & 18.2 \\
\hline Javanese & 75 & 17.9 & 20.8 \\
\hline Chinese & 8 & 1.9 & \\
\hline Mixed & 31 & 7.4 & 10.1 \\
\hline Dutch & 6 & 1.4 & \\
\hline Others & 12 & 2.9 & \\
\hline \multicolumn{4}{|l|}{ arity } \\
\hline O & 15 & 3.6 & \\
\hline $1-3$ & 92 & 22.0 & \\
\hline$>3$ & 66 & 15.8 & \\
\hline unknown & 246 & 58.7 & \\
\hline \multicolumn{4}{|c|}{ ge of first pregnancy } \\
\hline$<20$ & 22 & $5 \cdot 3$ & \\
\hline $20-30$ & 34 & 8.1 & \\
\hline $30-40$ & 5 & 1.2 & \\
\hline Unknown & 358 & 85.4 & \\
\hline
\end{tabular}




\section{Table 3: Tumor characteristics of breast cancer patients in Surinam}

6

\begin{tabular}{lcc}
\hline Strata & $\begin{array}{c}\text { Number of } \\
\text { patients }\end{array}$ & Percentage \\
\hline Total & $\mathbf{4 1 9}$ & $\mathbf{1 0 0 \%}$ \\
Type of tumor & & \\
Ductal & 394 & 94 \\
Lobular & 7 & 1.7 \\
Unknown & 18 & 4.3 \\
T-size & & \\
T1 $(\leq 20$ mm) & 98 & 23.4 \\
T2 $(>20, \leq 50$ mm) & 157 & 37.5 \\
$>$ T3 $(>50$ mm) & 96 & $\mathbf{2 2 . 9}$ \\
Unknown & 68 & 16.2
\end{tabular}

Number of involved axillary lymph nodes

No

$\mathrm{N} 1(1-3)$

N2(4-9)

$\mathrm{N}_{3}(\geq 10)$

Unknown
149

35.6

93

51

30

96
22.2

12.2

7.2

23.2 
ER/PgR

$\mathrm{ER}+/ \mathrm{PgR}+$

ER-/PgR-

$\mathrm{ER}+/ \mathrm{PgR}-$

ER-/PgR+

Unknown

Bloom-Richardson differentiation

Well $=$ grade 1

Moderately=grade 2

Poor=grade 3

Unknown

Mitotic Activity Index

$\leq 10$

$>10$

Unknown
26

39

2

2

350

7

52

181

179

51

44

324
12.2

10.5

6.2

9.3

0.5

0.5

$83 \cdot 5$

1.7

12.4

43.2

42.7

$77 \cdot 3$

1

2

3

4

5

6

7

8

9

10

11 
Table 4: Therapy characteristics of breast cancer patients in Surinam

\begin{tabular}{|c|c|c|c|c|c|}
\hline & $\mathrm{n}$ & $\%$ & $\begin{array}{l}\text { Lymph node } \\
\text { positive }\end{array}$ & \multicolumn{2}{|c|}{$\begin{array}{l}\text { Lymph nodd } \\
\text { negative }\end{array}$} \\
\hline Total & 419 & 100 & & & 12 \\
\hline Surgery & 334 & 79,7 & & & 13 \\
\hline - Mastectomy & 292 & 69,7 & 150 & 127 & 14 \\
\hline - Lumpectomy & 42 & 10,0 & 14 & 20 & 15 \\
\hline Radiotherapy & 59 & 13,8 & 33 & 24 & 16 \\
\hline - after lumpectomy & 33 & 7,9 & 20 & 16 & 17 \\
\hline - after mastectomy & 26 & 5,9 & 13 & 8 & 18 \\
\hline Chemotherapy & 86 & 20,5 & & & 19 \\
\hline - CMF & 45 & 10,5 & 35 & 4 & \\
\hline - Anthracycline-containing & 31 & 7,9 & 21 & 7 & \\
\hline - Unknown & 10 & 1,9 & & & 21 \\
\hline Hormone therapy & & & & & 22 \\
\hline (Tamoxifen) & 216 & 51,6 & 107 & 76 & 23 \\
\hline
\end{tabular}


2

3 Figure 1: Age specific breast cancer incidence in Surinam and in Surinamese 4 women in the Netherlands

6

8

9

10

11

12

13

14

15

16

17

18

19

20

21

22

23

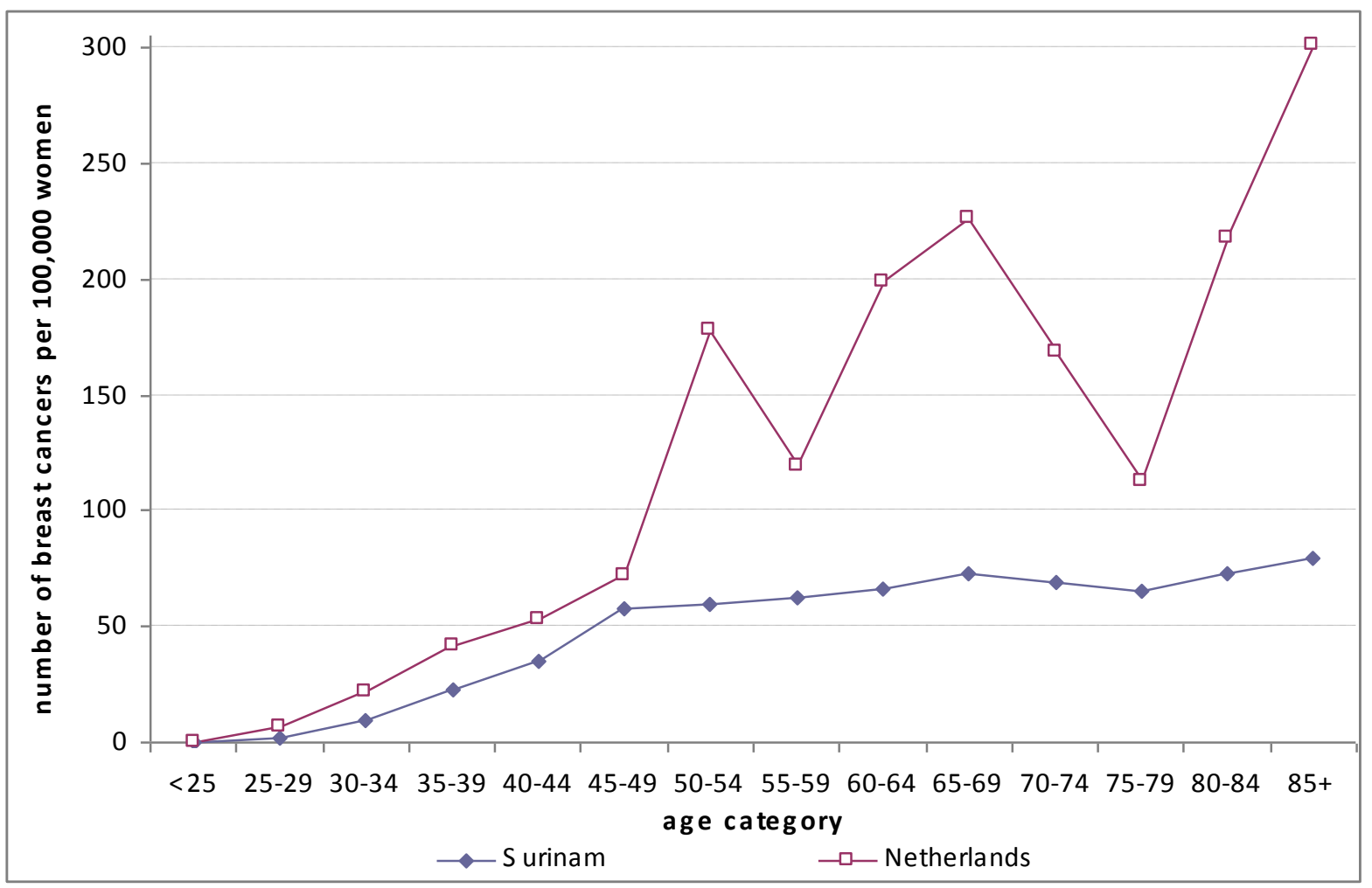

8

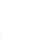

(1)

(1)

4

5

17

Figure 2: Overall $\&$ disease free survival of all patients 


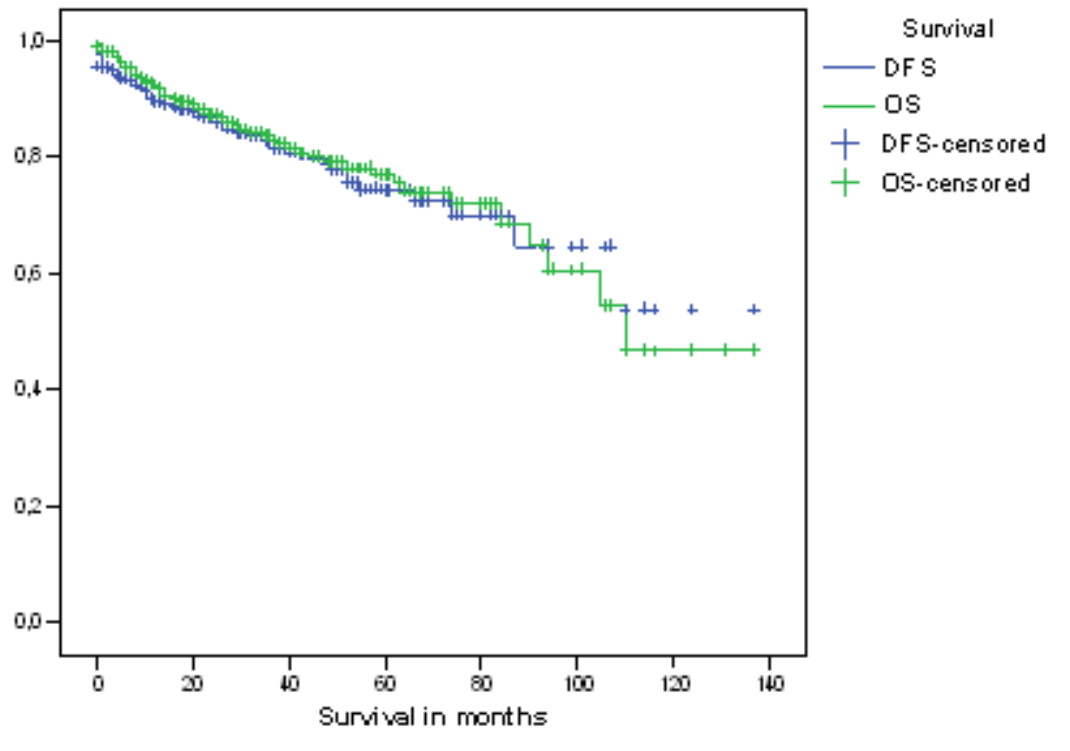

1

3

4 Figure 3: Overall cumulative survival of patients with $\mathrm{NO} / \mathrm{N}+$

5

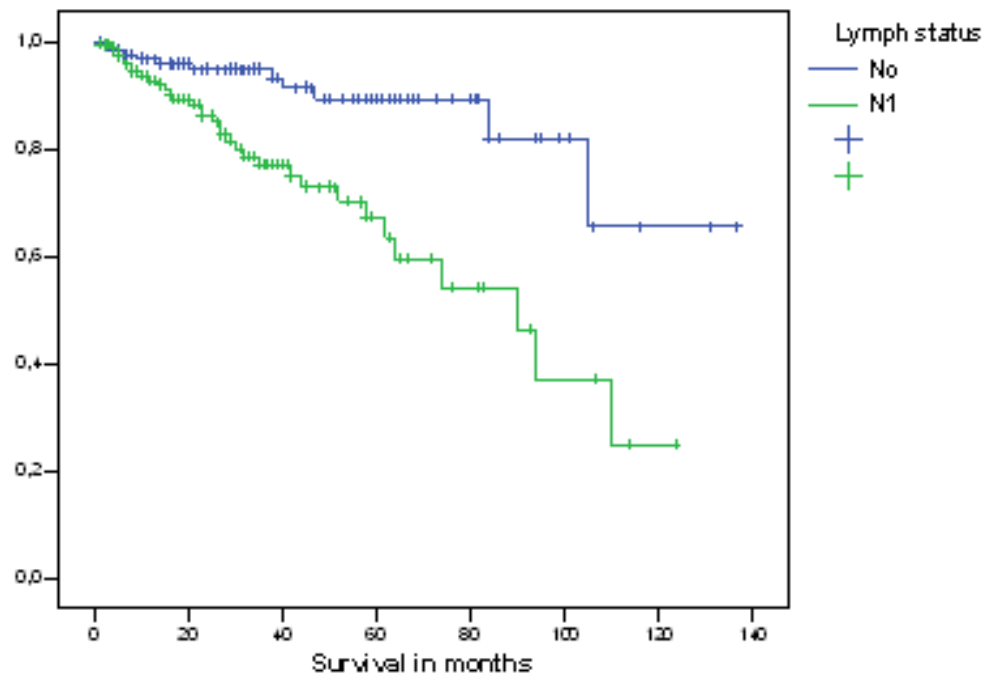

6

7

8 